\title{
Capsule Dosage Form
}

National Cancer Institute

\section{Source}

National Cancer Institute. Capsule Dosage Form. NCI Thesaurus. Code C25158.

A solid contained within either a hard or soft soluble shell, usually prepared from gelatin. 